Мельников Михаил Васильевич

кандидат социологических наук, доцент кафедры социологии Новосибирского государственного технического университета, доцент кафедры социологии

Новосибирского государственного университета экономики и управления (HИНХ)

\section{СОЦИОЛОГИЧЕСКАЯ СЕМАНТИКА ПРИВАТИЗАЦИИ [1]}

Аннотация:

В статье предпринята попытка краткого анали тического обзора некоторых подходов применения понятия «приватизация» для объяснения социальных явлений и процессов. В рассмотренных подходах выделены несколько существенных сторон понятия приватизации, позволяющих определить контуры его использования в социологии.

Ключевые слова:

приватизация, дихотомия приватного и публичного, социальный процесс, отчуждение, присвоение, социальное состояние, социальная проблема, социальный механизм.
Melnikov Mikhail Vasilyevich

PhD in Social Science, Assistant Professor, Social Science Department, Novosibirsk State Technical University, Assistant Professor, Social Science Department, Novosibirsk State University of Economics and Management

SOCIOLOGICAL SEMANTICS OF PRIVATIZATION [1]

Summary:

The article presents a brief analytical overview of some approaches to the application of the privatization concept for explanation of social phenomena and processes. The author distinguishes some significant aspects of the privatization concept in these approaches allowing to define the framework of its application in the social science.

Keywords:

privatization, dichotomy of private and public, social process, alienation, appropriation, social condition, social problem, social mechanism.

Новый интерес к обсуждению перспектив приватизации в России нескольких сотен унитарных госпредприятий и акционерных обществ может представлять собой подходящий повод для того, чтобы еще раз попытаться разобраться в значении понятия «приватизация» и определить сущность соответствующего социального процесса. Традиционно приватизация трактуется как передача или продажа в частное использование управления общественными службами, институтами, собственностью. Приверженцы такого видения указывают, что исследование приватизации с позиций идеологических и социальных изменений «не позволяет понять экономическую природу приватизации, а лишь отклоняет наши устремления в область социологии» [2, с. 16]. На самом деле иное, в нашем случае - социологическое, изучение приватизации позволит увидеть те ее стороны, на которые экономическая наука и шире - экономический разум не обращают внимание.

В настоящее время широко известна в основном экономическая трактовка приватизации. Сведение значения понятия исключительно к экономике, по нашему мнению, необоснованно сужает его содержание. В этом случае не представляется возможным, как мы полагаем, дать комплексную оценку приватизации как сложному социальному феномену. Подобная оценка осуществима, если отказаться от интерпретации приватизации как лишь экономического феномена. Обоснование социологического истолкования связано с перспективами социологического изучения дихотомии приватного и публичного. Процесс, выражаемый с помощью категории «приватизация», является одной из базовых характеристик, посредством которой общественное развитие можно изучать как дифференциацию приватного и публичного. Так доказывается обоснованность расширенного объяснения приватизации как социального процесса, наиболее изученного с экономической стороны.

В настоящей статье предпринята попытка выполнить обзор некоторых подходов применения понятия «приватизация» для объяснения социальных явлений и процессов, а не экономических. Один из ранних примеров использования рассматриваемой нами категории в социологической трактовке обнаружен в книге Н. Элиаса «Общество индивидов» 1939 г. Автор пишет, что наряду с всеохватывающим сдвигом к индивидуализации в Европе в XV-XVII вв. наблюдался переход от зависимой от внешних авторитетов совести к совести, которую можно назвать более «индивидуальной» и автономной. Люди были склонны скрывать от других, а может быть, и от себя свои стремления и желания. Одним из следствий этих изменений стал внутриличностный конфликт. Для раскрытия его сути Н. Элиас и воспользовался термином «приватизация» [3, с. 172].

Критическую, даже клиническую характеристику процессу приватизации в связи с распадом публичного пространства и сопричастности людей друг другу в сознании, действии, символах и чувствах дает Х. Арендт. Этот распад происходит как в тоталитарных обществах, так и в 
массовых, а также в ситуациях повальных истерий. «В обоих случаях мы имеем дело с радикальными феноменами приватизации, т. е. с состояниями, в которых никто уже не может видеть и слышать другого или быть увиденным и услышанным» [4, с. 76].

Термин «принужденная приватизация» (enforced privatization) применял Д. Рисмен для выражения экономического, иерархического, семейно-брачного ограничений, препятствующих людям в выражении и развитии их индивидуальности в форме отдыха, игры, дружбы и т. д. Конкретный вид выражения содержания этого понятия, используемый Д. Рисменом, - приватизация женщин, детей и низших классов, т. е. иммобилизация, невозможность покинуть пределы частной сфреры в силу бедности, традиции, низкого статуса. «Героиня "Позволь выйти сегодня вечером" примерзла к своему коттеджу в пригороде, она отрезана от всего рынка дружбы и с мужчинами, и с женщинами, за исключением тех, которые социально связаны с ее мужем. Но многим жительницам пригородов и фермерским женам еще хуже. Муж ездит на работу на единственной машине, которая есть в семье, а его жена остается в доме как узница вместе с малолетними детьми, телефоном, радио или телевизором. Такие женщины могут легко стать настолько неинтересными, что они останутся заключенными и ограниченными в своих действиях и в своих душевных движениях даже тогда, когда и физические, и экономические помехи для их мобильности уже исчезнут» [5, р. 282].

К таким же выводам на основании собственного анализа чикагских семей среднего класса пришел Р. Сеннет. «Другие исследователи, занимавшиеся положением женщины, в конце концов стали рассматривать функции нуклеарной семьи в XIX столетии в том же свете, в качестве места для удаления женщин и детей из общества, сразу и подавлявшего их, и дававшего им приют. Марксистские идеи приватизации обрели новую жизнь в теоретических трудах таких ученых, как Джуллиет Митчелл и Маргарет Бенсмен, исчерпывающее исследование сочинений XIX в. об уходе за детьми, о проблемах супружества и об образах семейной жизни показало, что идеология удаления женщины из общества на протяжении столетия становилась все сильнее» [6, с. 198]. Р. Патнэм в книге «Боулинг в одиночку» применяет понятие «приватизация» для выводов о последствиях падения социального капитала в США. По его словам, «телевидение и развлекательные программы глубоко приватизировали свободное время» американцев за счет социальной и групповой активности [7, р. 372]. Все указанные авторы оценивают приватизацию критически, поскольку она способствует снижению солидарности и гражданственности в современном обществе.

Однако известны трактовки сути и общественного значения приватизации, которые можно охарактеризовать как ценностно-нейтральные. Например, Дж. Урри в книге «Мобильности» пишет о «приватизированном» приращении движущегося тела человека, достигаемом и развиваемом посредством iPod, лэптопа, DVD-плейера и мобильного телефона, используемых, например, для приема телепередач [8, с. 325]. В другой работе Дж. Урри оперирует термином «приватизация» в таком же значении применительно к автомобилю [9, с. 95]. Э. Шенфельд относит содержание рассматриваемой категории к области религии и процессу индивидуализации. Понятие «приватизация» применяют для выражения мысли о том, что религиозные верования суть субъективные, идиосинкразические и частные выражения веры. Также приватизация истолковывается как один из аспектов секуляризации. Выражение религиозной веры становится менее публичным. Человек в одиночестве переживает опыт приобщения к чему-то, что именуется и идентиоицируется как Божественное [10]. Дж. Бест пишет о приватизации применительно к социальным проблемам. Когда возникают новые вопросы о какой-либо проблеме, люди обращаются за интерпретациями к ее «собственникам», т. е. персонам, получившим признание благодаря конструированию проблемы, ее масштаба, причин, решений и того, что Дж. Бест называет утверждениями-требованиями. Их успешное выдвижение может привести к приватизации социальной проблемы ее «собственниками». Они обнаруживают, что в их власти расширить сореру «своей» проблемы. Благодаря этому «собственники» проблемы получают широкое признание и обретают влиятельность [11, с. 36].

В рассмотренных подходах к применению понятия «приватизация» для изучения социальных явлений и процессов можно выделить несколько существенных сторон толкования данной категории, позволяющих определить его контуры в рамках социологии. Термин «приватизация» используется как для исследования социальной динамики общества, социальных процессов, так и для выражения особого состояния, в котором пребывает или желает пребывать человек. Изучение приватизации как состояния возможно, если связывать его с анализом приватности, имеющей разнообразные формы. Одни из них не связаны с ограничениями личностной свободы, например добровольным уединением. Другие, напротив, выражают разные стороны социальной эксклюзии. К таким формам можно отнести социальную изоляцию личности и отчуждение, с примером которого мы познакомились в работе Д. Рисмена.

Также понятие «приватизация» применяется для выражения идеи нелегитимного, несогласованного и в целом вызывающего в обществе осуждение присвоения общественных ресурсов и благ. 
К последним можно отнести не только природные ресурсы, государственные предприятия, но и открытые общественные пространства. Приватизация как присвоение есть превращение в частное и недоступное чего-то, что раньше было открыто-публичным, общедоступным. Характеристика приватизации как отчуждения наиболее близка критике экономической стороны приватизации.

Кроме того, применение понятия приватизации для выражения содержания социальных процессов также может быть весьма плодотворным. Обращение к дихотомии приватного и публичного и выбор терминов, посредством которых выражается суть элементов данной дихотомии, относительно социальных процессов позволяют заметить следующее. Как приватное (частное) противоположно публичному (общественному), так приватизация противоположна обобществлению, политизации и социализации. Социологическая сущность приватизации может быть выражена, соответственно, с помощью категорий деполитизации и десоциализации. Приватизация политики в этом случае может трактоваться как превращение ее из деятельности, направленной на защиту и приумножение общественных благ, в деятельность, преследующую интересы меньшинства. Открытый доступ к ней ограничивается, а общественный контроль над ней становится практически невозможным. Интересы правящего класса, так называемой элиты, изменяются в сторону снижения ее ответственности за общество и «приватизации» ее интересов. Выразителями подобной трансформации являются продолжаемый экономической «элитой» процесс приватизации общественной собственности и начатый управленческой «элитой» процесс «приватизации» государства - постепенного сокращения выполнения им социальных функций для большинства населения и одновременного увеличения частных расходов представителей «элиты» за общественный счет.

В то же время понятие «приватизация» используется для выражения идеи социального механизма, служащего адаптации людей к пугающим их изменениям. В этом случае она рассматривается в связи с другими социальными процессами как ответная реакция на социальные перемены. Повышение ценности частного бытия в последние десятилетия можно объяснить как реакцию отдельных людей против многовекового подчинения государству и традиционным институтам. Стремление приватизировать общественные блага, поддерживаемое многими людьми, и возрастание численности собственников имеют не только экономические причины, но и психологические. В современном мире обладание собственностью придает человеку гарантии личной защищенности и безопасности. Однако при этом не следует отказываться от вывода о том, что преимущество и эксклюзивность пользования приватизируемыми общественными благами и пространствами могут маскироваться апелляцией локального сообщества (прежде всего собственников), заинтересованного в создании комфортного и безопасного режима управления своей территорией, к представлению о кооперативном благе как форме общего блага.

\section{Ссылки и примечания:}

1. Статья подготовлена при финансовой поддержке РГНФ. Грант 16-03-00348 «Приватизация публичного пространства: социальные истоки, формы и последствия» (2016-2018).

2. Сокольский А.А. Институциональная природа приватизации. М., 2004.

3. Элиас Н. Общество индивидов. М., 2001.

4. Арендт X. Vita activa, или О деятельной жизни. СПб., 2000

5. Riesman D., Glazer N., Denney R. The Lonely Crowd. New Haven ; London, 1966.

6. Сеннет Р. Коррозия характера. Новосибирск, 2004.

7. Putnam R. Bowling Alone: America's Declining Social Capital [Электронный pecypc]. URL: http://www.directoryonline.com/Rotary/Accounts/6970/Downloads/4381/Bowling\%20Alone\%20Article.pdf (дата обращения: 28.12.2016).

8. Урри Дж. Мобильности. М., 2012.

9. У Ури Дж. Социология за пределами обществ: виды мобильности для XXI столетия. М., 2012.

10. Schoenfeld E. Privatization and Globalization: a Durkhemian Perspective on Moral and Religious Development // Archives de sciences sociales des religions. 1990. No. 69. P. 27-40.

11. Бест Дж. Социальные проблемы // Социальные проблемы: конструкционное прочтение. Хрестоматия. Казань, 2007. C. 26-54.

\section{References:}

Arendt, $\mathrm{H}$ 2000, Vita activa or the active life, St.-Petersburg, (in Russian).

Best, J 2007, 'Social problems', Sotsial'nyye problemy: konstruktsionnoye prochteniye. Khrestomatiya, Kazan, pp. 26-54, (in Russian).

Elias, N 2001, The society of individuals, Moscow, (in Russian).

Putnam, R 2016, Bowling Alone: America's Declining Social Capital, viewed 28 December 2016, <http://www.directoryonline.com/Rotary/Accounts/6970/Downloads/4381/Bowling\%20Alone\%20Article.pdf>, (in Russian).

Riesman, D, Glazer, N \& Denney, R 1966, The Lonely Crowd, New Haven, London, (in Russian).

Schoenfeld, E 1990, 'Privatization and Globalization: a Durkhemian Perspective on Moral and Religious Development', Archives de sciences sociales des religions, no. 69, pp. 27-40, https://doi.org/10.3406/assr.1990.1312.

Sennett, R 2004, The corrosion of character, Novosibirsk, (in Russian).

Sokolsky, AA 2004, Institutional nature of privatization, Moscow, (in Russian).

Urry, J 2012a, Mobility, Moscow, (in Russian).

Urry, J 2012b, Sociology beyond societies: mobilities for the twenty-first century, Moscow, (in Russian). 